\title{
Los conceptos de un urbanismo moderno como modelo para una planificación sustentable. Plan Regulador Antofagasta (1965-2002) y Seccional la Chimba (2001), Chile
}

\author{
Valeska Cerda Fuentes ${ }^{1}$, Francisca Araya Fuentes ${ }^{2}$ \\ Escuela de Arquitectura, Universidad Católica del Norte. Antofagasta, Chile \\ E-mail: ${ }^{1}$ valeska.cerda@ucn.c, ${ }^{2}$ francisca.araya@ce.ucn.cl,
}

\begin{abstract}
Resumen. De las definiciones del primer Plan Regulador Comunal de Antofagasta (PRCA) promulgado en el año 1965 y la configuración de algunos conjuntos habitacionales modernos relevantes construidos en la ciudad de Antofagasta entre los años 1939 y 1978, es posible reconocer algunos principios básicos del urbanismo moderno como Zoning" y "Neighborhood Unit" planteados por Clarence Perry en el año 1923. Principios que proponen desde una trama densificada por manzanas abiertas que favorece la consolidación del espacio público, intenciones que promueve el nuevo urbanismo. En contraste con lo anterior se compara la configuración actual de las zonas de expansión y desarrollo de proyectos habitacionales en la ciudad de Antofagasta, se analiza la propuesta de los instrumentos de planificación como el Plan Seccional La Chimba (PSCH) vigente desde el año 2001. Desde esta condición se hace presente en las zonas de expansión de la ciudad de Antofagasta una fisonomía no compleja con macro-manzanas mono-funcionales cerradas. Se abre la discusión sobre la no consideración en las definiciones de los instrumentos de planificación actual para las zonas de expansión residencial urbana, en cuanto a la a la dimensión de las manzanas, su densificación y diversificación de programa.
\end{abstract}

Palabras clave: Planificación, barrio, densificación, sustentable, urbanismo moderno.

\section{Introducción}

La ciudad de Antofagasta desde el año de su fundación en 1868 fue el salitre y la plata sus recursos minerales más preciados, luego en el siglo XIX en los años 30 y 40 con la crisis salitrera es el mineral del cobre que toma fuerza. Sin embargo es en este siglo en los años 50 que la ciudad alcanza una población de 51.107 habitantes continuando su auge y aumentando en los años 60 un crecimiento importante en su población a 87.860 habitantes (Censo 1963). El auge económico en el siglo XIX de los años 50 y 60 relacionado con la explotación del mineral del cobre posiciona a Antofagasta como la ciudad puerto más importante de la Región lo cual potencia la construcción de importantes proyectos de servicios públicos, educacionales, de salud y de vivienda. Sin embargo, a pesar de este desarrollo la ciudad no contaba con una planificación territorial general o un planteamiento de lo que se quería como ciudad. Hasta este momento la ciudad se manifestaba la expansión de las periferias norte y sur de la ciudad, siendo en el año 1965 promulgado el primer Plan Regulador Comunal de Antofagasta (PRCA), elaborado por Jorge Poblete Grez de TAU arquitectos. Por entonces, ya presenta una idea de urbanismo moderno con la introducción de conceptos como "Centro Vecinal" y de agrupamiento como "Bloque Armónico". Sin embargo, en su segunda versión del año 1981 estos conceptos son derogados. De las siguientes versiones de 


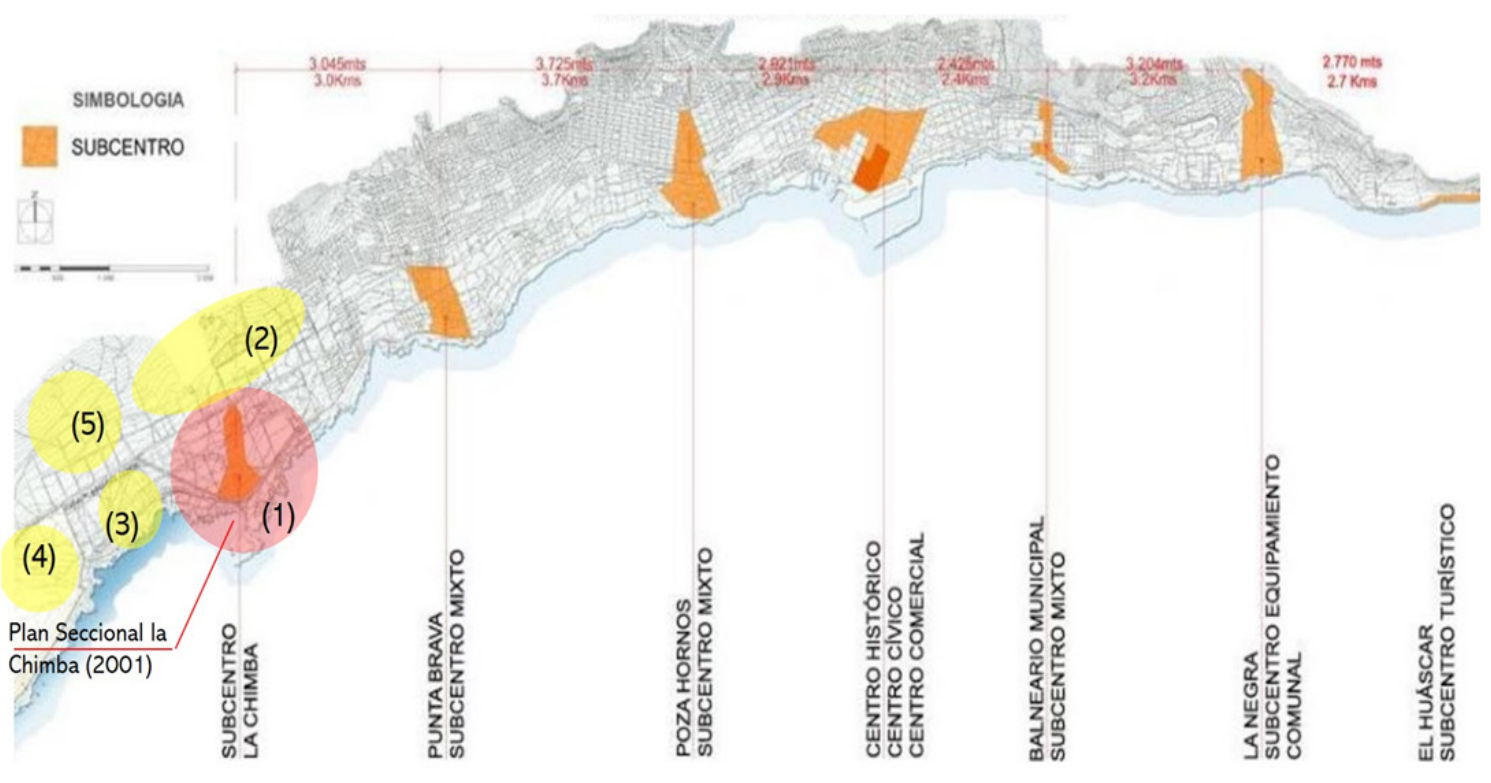

Fig. 1. Subcentros y Plan Seccional la Chimba. (Memoria MPRCA, archivo V.Cerda).

este Plan se destaca la del año 2002, donde se concreta el concepto de "transeptos". Esta noción incorpora la formación de subcentros transversales configurados por una diversidad de equipamientos públicos $\mathrm{y}$ privados, conectando las vías longitudinales estructurantes del borde costero y del borde cerro definidas en el primer PRCA. Además de estos subcentros se establece el sector norte como la zona de extensión urbana con más proyección y es organizada en cinco macrozonas para desarrollar algunos Planes Seccionales y estudios de planificación como se indica en la figura 1: La Chimba año 2001 (1), La Chimba Alto (2), Portada Sur (3), Portada Norte (4) y la Portada Alta (5).

Esta intención de descentralizar nos lleva a reflexionar que sería posible una planificación de una ciudad densificada y compacta y por lo tanto sustentable.

\section{Buenas prácticas de planificación primer PRCA (1965) y preexistencias de conjuntos habitacionales modernos en zonas de expansión.}

Entre los años 1939 y 1978 en la ciudad de Antofagasta se desarrollaron relevantes obras de conjuntos habitacionales modernos para resolver el déficit habitacional, de una escala urbana y generan transformaciones urbanas que dan pie a la construcción de una nueva planteamiento de ciudad. Este planteamiento tiene en esencia las ideas de urbanismo moderna. Entendido esto desde las referencias de Clarence Perry (1923), Jane Jacobs (1961) y posteriormente Kevin Lynch (1960), los cuales declaran la idea de una ciudad ordenada y democrática y que desctaca el rol de la calle no solo como ejes estructuradores de la trama urbana, sino que también como el espacio público de uso común soportada por una mixtura programática.

Inicialmente, C. Perry propone una planificación entorno a una mixtura de programática de los edificios que configuran la manzana y donde la proximidad entre estos permite que la vida del habitante con tiempos para la recreación y accesibilidad a edificios de servicios, abordando todo esto en distancias abordables reconociendo la ciudad por medio de calles internas que finalmente conectan con vías estructurantes de la ciudad.

De esta visión se encuentran similitudes con lo planteado por Jane Jacobs en su libro "Muerte y vida de las grandes ciudades"(1961) que declara que la actividad de los habitantes es motor fundamental del uso de los espacios públicos y donde la planificación no se resuelve "desde arriba", sino más bien, desde el plano en 
donde se desarrolla la vida; donde la manzana es la unidad básica de la ciudad, la que debe otorgar espacios para el encuentro de las personas siendo la calle el principal aglutinador de la vida de barrio y de las distintas realidades sociales, logrando así una relación y confianza de vecindario en los espacios compartidos como estrategia de seguridad para el conjunto. En este sentido Kevin Lynch en su libro "The image of the city" (1960) también hace un aporte significativo coherente con lo defendido por Jacobs. Propone un entendimiento de la ciudad mediante la mixtura de partes que la componen, desde el uso e identificación de parte del habitante, resolviendo que se debe generar una imagen clara no estratificada, sino más bien estimulante, abierta y que invite a las personas a usarla y percibiendo su entorno. Desde esta idea construida por las miradas de Perry, Jacobs y Lynch, se presentan como buenas prácticas de planificación e intervención, el primer PRCA (1965) y las preexistencias de conjuntos habitacionales modernos, las cuales desde una necesidad de soslayar un déficit habitacional de la época plantean y proponen una disposición que genera relaciones espaciales, funcionales y ambientales con la trama de la ciudad.

\section{Particularidades del primer PRCA (1965).}

Es posible identificar en lo descrito en el PRCA (1965) principios que se reconocen de corte moderno y que detallan sobre los límites urbanos, zonificación y del destino de las zonas, características y sistema de agrupamiento. Ideas que son tratadas por C. Perry (1923) en su concepto de "Neighborhood Unit" como: límites, sistemas de calles interiores, tamaño, espacios abiertos, sitios de la institución y tiendas locales.

\section{Límites y Sistema de calles interiores.}

En el Título II del PRCA se declara el concepto de límite y sistema de calles interiores de C. Perry, y se describen los límites urbanos, formalizando una de las primeras particularidades del ordenamiento de la ciudad que tiene relación con su geografía definiendo dos ejes estructurantes longitudinales norte-sur: la del borde costero y la del borde cerro. Desde estos dos ejes se vinculan vías secundarias transversales y de éstas las calles interiores que conectan los diversos sectores definidos en el PRCA.

\section{Tamaño, Sitios de institución y Tiendas locales.}

En cuanto a los conceptos de C. Perry sobre tamaño, sitios de institución y tiendas locales, se describe en el Título III sobre la zonificación y del destino de las zonas, destacando tres áreas que incluyen el uso de suelo mixto organizando tres áreas; Área residencial, que incluye programa habitacional, educacional y religioso; Área comercial, que propone en primer piso locales comerciales y artesanías

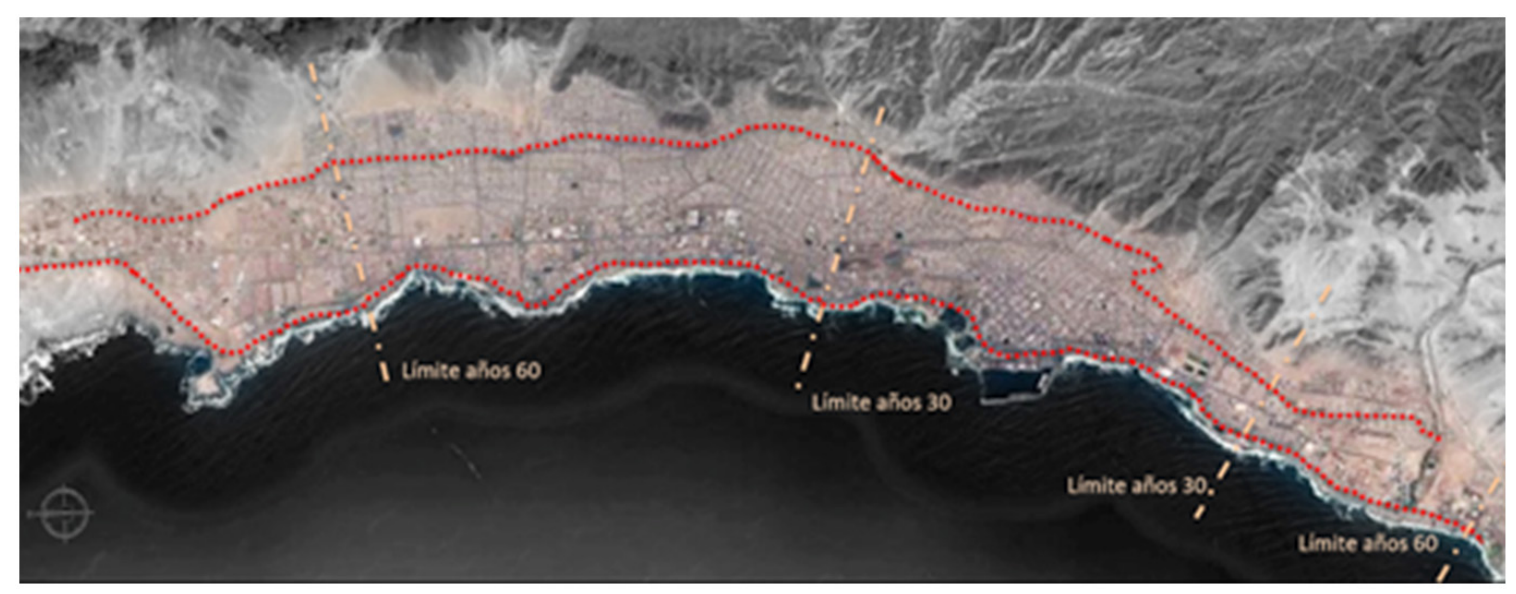

Fig. 2. Extensión longitudinal de la ciudad, límites años 30 y 60 del siglo XIX.

Google Earth 2018, archivo V. Cerda. 
no molestas y en pisos superiores programa habitacional; Áreas de Centros Vecinales, destinadas a la ubicación de edificios de equipamiento administrativo, asistencial, comercial en el primer piso recreativos y pisos superiores departamentos, edificios que conforman con su emplazamiento espacios de áreas verdes o plazas de juegos infantiles de descanso. Tal como indica C. Perry en su idea de la Unidad Vecinal como centro que cuente con los programas esenciales para el habitante, con posibilidad de una accesibilidad segura desde su zona habitacional a estos distintos servicios.

Espacios abiertos. En el Título III del PRCA, se detalla acerca de las características de la edificación en las diferentes zonas y sobre el sistema de agrupamiento, donde se destaca desde el concepto moderno de C. Perry la importancia de generar pasajes peatonales, accesibles que permitan una circulación segura de los habitantes de la Unidad Vecinal. Esta condición es posible con la configuración de un espacio público contenido por bloques de edificios dispuestos en manzanas de orden abierto. Este tipo de agrupamiento es propuesto en el PRCA como "Bloque Armónico", agrupamiento que se explica como: "Aquella que, regida por una planificación del total, agrupa o dispone los diferentes cuerpos de las edificaciones, formando una composición arquitectónica de conjunto". (PRCA, 1965: Art.28).

Desde esta idea de espacios abiertos identificados en el PRCA se destacan en la trama de la ciudad dos preexistencias, ambos conjuntos habitacionales realizados antes de la promulgación del PRCA pero que ciertamente son referencias para la definición del tipo de áreas de "Centros vecinales" y agrupamiento de "Bloque Armónico" propuesto.

\section{Conjunto habitacional Gran Vía (1954- 1978). Arquitectos Ricardo Pulgar, Germán Cartagena y Sergio Gaete.}

Este conjunto habitacional se extiende en un terreno de $276.560 \mathrm{~m} 2(27,65 \mathrm{ha})$ y está conformado por bloques de departamentos (edificios Huanchaca y Caliche), una torre de
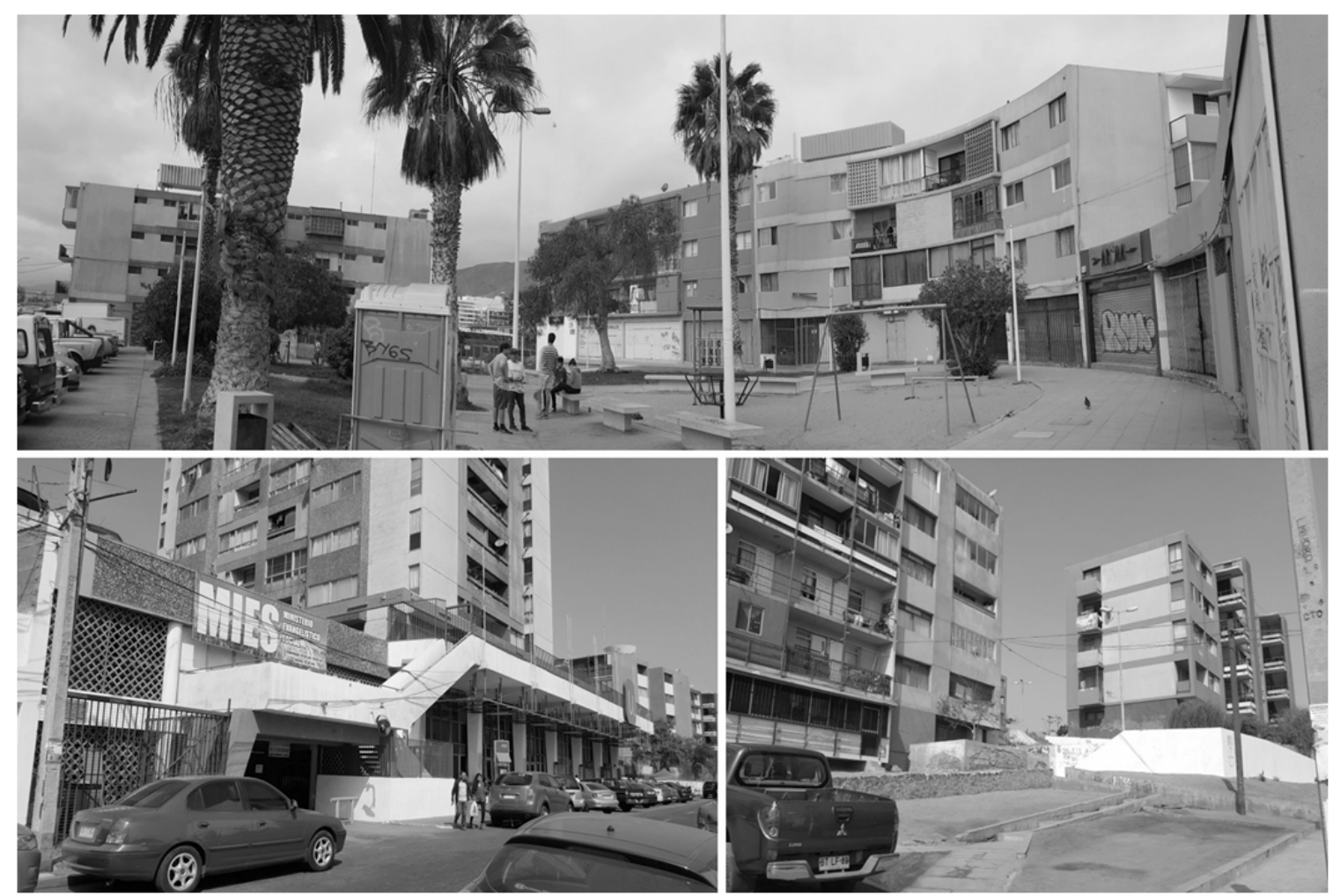

Fig. 3. Conjunto habitacional Gran Vía (archivo V.Cerda). 
24 pisos (torre Pérez Zujović), un grupo de viviendas de baja densidad y equipamiento comercial. Según lo planteado por C. Perry, se hace evidente en este proyecto la intención de establecer límites desde la generación de una mixtura programática que incluye un grupo de viviendas, una escuela, una iglesia, teatro, mercado, centro médico, estación de automóviles y un retén de Carabineros y que constituyen una trama urbana clara y ordenada conectada por medio de calles interiores que se integran a un gran parque central de una propositiva fisonomía, el que daría cabida a espacios de encuentro y recreación entre los habitantes.

\section{Límites y Sistema de calles interiores}

En cuanto a la configuración de límites y calles internas estas son generadas por volúmenes que varían en su escala y orden con dos edificios de escala mayor como el Huanchaca y Caliche, que por su interesante forma lineal y su imponente escala, definen límites en el conjunto y proporcionan extensas terrazas que permiten la articulación de los niveles en los que se emplaza el conjunto y el descubrimiento en altura de la ciudad y su trama, llevando al usuario al reconocimiento del conjunto y sus partes, enmarcados por el contexto y paisaje. Sumado a esto, la torre Pérez Zujović se presenta como elemento icónico que marca un punto en el espacio. Las viviendas de baja densidad constituyen sendas mediante calles interiores que ordenan y direccionan hacia el encuentro con los edificios antes mencionados. En esa relación de escalas en donde se genera el vínculo entre arquitectura y ciudad, donde las calles internas provenientes de la trama urbana se hacen parte del edificio, y desde el edificio se hacen parte de la trama urbana.

Espacio abierto El Conjunto se articula mediante vacíos o espacios colectivos públicos resultantes de volúmenes agrupados $\mathrm{y}$ distanciados entre ellos que generan manzanas abiertas, los cuales reciben desde la escala de las viviendas y articulan hacia los accesos de los edificios, en donde surgen otros espacios colectivos públicos abiertos

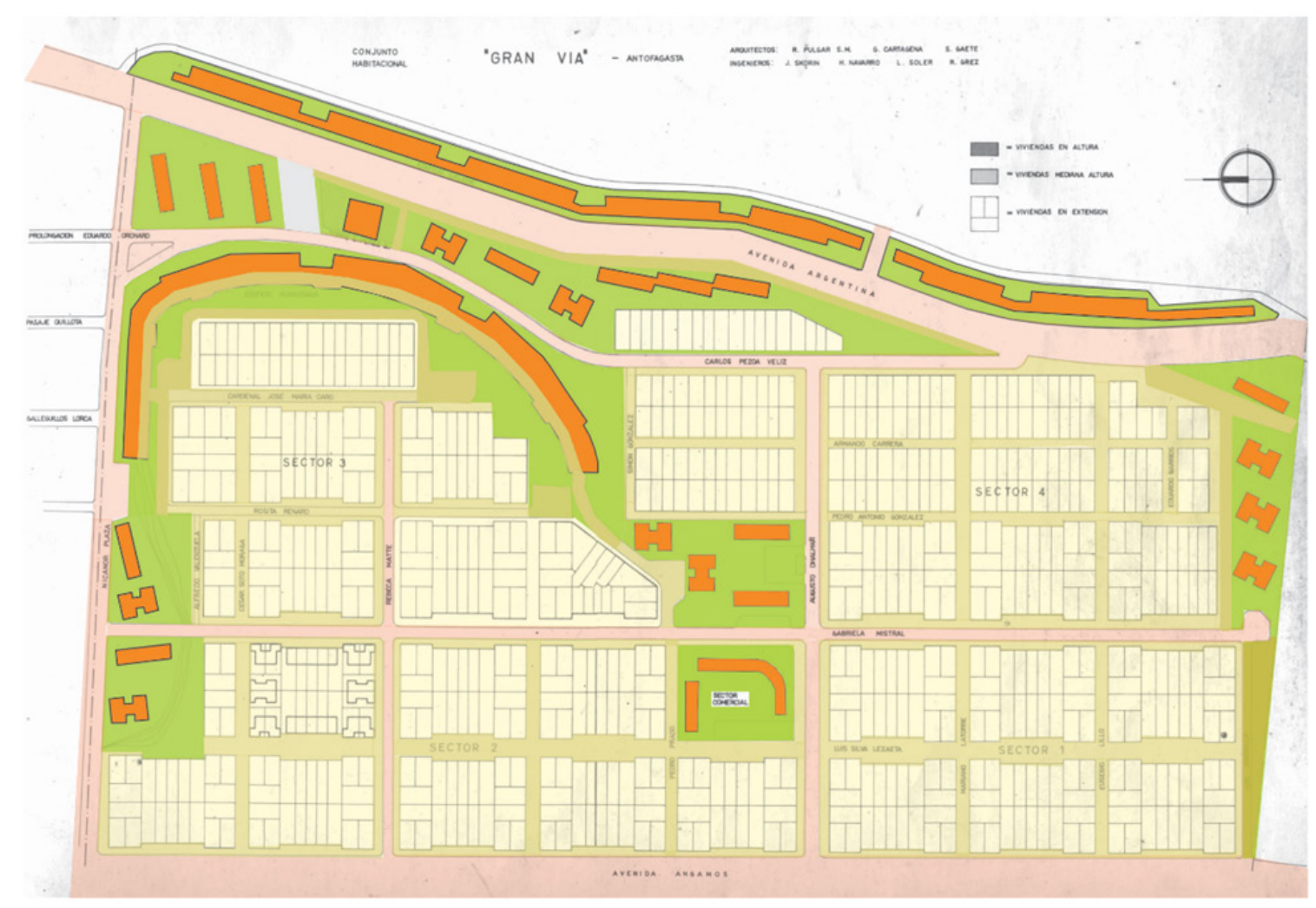

Fig. 4. Plano conjunto habitacional Gran Vía. Elaboración propia. 

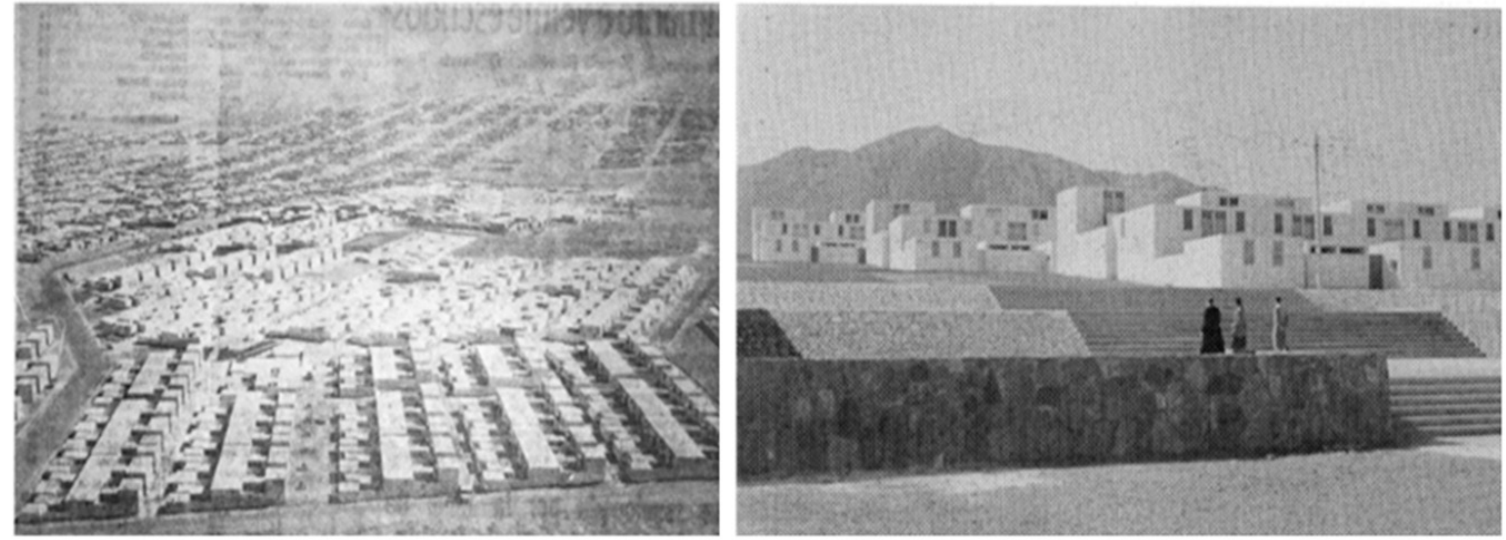

Fig. 5. Conjunto Salar del Carmen, 1962-63. Archivo El Mercurio de Antofagasta y M. P. de Arce

en altura, generando un sistema de habitar que proporciona instancias de traspaso desde el exterior, mediante espacios intermedios $\mathrm{y}$ hacia el interior, y viceversa. Es en esa posibilidad de constante traspaso en donde se evidencia el planteamiento de un sistema de habitar estructurado por espacios abiertos que vinculan la ciudad con la unidad vecinal y además proporcionan espacios de encuentro de los ciudadanos.

\section{Conjunto Habitacional Salar del Carmen (1959-1961). Arquitectos Mario Pérez de Arce y Jaime Besa.}

Este conjunto habitacional se compone por 850 viviendas y se emplaza en la pendiente del sector Quebrada y Salar del Carmen, con una extensión de $228.254 \mathrm{~m} 2$ (22,82 ha). Este conjunto no se compone por volúmenes de mayor escala, sin embargo, se pueden identificar valores medioambientales desde lo planteado por C. Perry en cuanto a la dimensión humana desde la construcción de calles interiores su peatonalización y construcción de un centro común que incluye un colegio y centro social.

\section{Límites y Sistema de calles interiores.}

El Conjunto se delimita mediante vías estructurantes de la trama urbana y se configura mediante grupos de viviendas de baja altura que en su interior incluyen un patio sombreado. Los grupos de viviendas se orientan y disponen de manera tal que generan pasajes internos sombreadas y ventilados para proteger a los habitantes de las condiciones climáticas del desierto. Estos pasajes se caracterizan por presentar dimensiones controladas que acogen la escala del cuerpo y propician la interacción social y la apropiación de este espacio público que se conectan con otros espacios de esparcimiento como plazas el centro comunitario y equipamiento educacional.

Espacio abierto. Mediante la variación en la disposición de los grupos de viviendas que componen el conjunto, es posible identificar un orden de quiebres y encuentro de tramas donde se generan espacios abiertos que propician el encuentro de los habitantes y donde mediante el escalonamiento del conjunto se resguarda al peatón del paso vehicular y es posible en su recorrido el reconocimiento del contexto y del paisaje antofagastino.

\section{Intervenciones actuales en zonas de extensión urbana, caso Plan Seccional la Chimba (PSCH), 2001.}

En el PRCA se identifica la zona norte con mayor superficie edificable y es donde se desarrollan Planes Seccionales y estudios de planificación que abordan una superficie de $3.064,17$ ha el 39\% de la superficie del área urbana de la ciudad de Antofagasta (7.899,41 ha). De estos proyectos de planificación se encuentra vigente desde el año 2001 el Plan Seccional la Chimba (PSCH), instrumento complementario del PRCA del año 2002 que declara una planificación de orden lineal y que busca la descentralización de la ciudad 


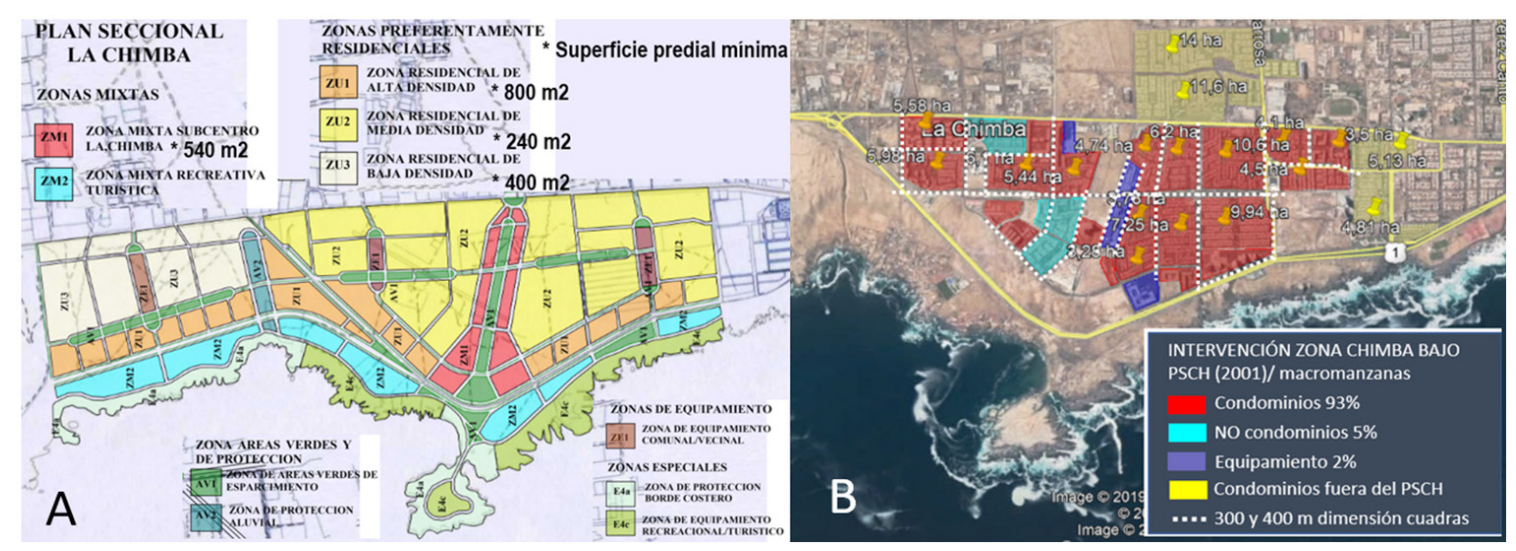

Fig. 6. (A) Zonificación superficies prediales mínimas PSCH, 2002.

(B) Intervención conjuntos habitacionales, régimen de copropiedad. (archivo V.Cerda).

por medio de "transeptos", entendidos como centros transversales o subcentros que definen unidades territoriales, configurado con equipamiento público y privado diverso, mejorando así la conectividad, la consolidación de las dinámicas propias de cada sector y la consolidación del espacio público

Sin embargo, los proyectos inmobiliarios que se han ejecutado en la zona planificada por el PSCH, no ha sido propicio para la consolidación de dichos subcentros y se ha generado una trama urbana que incurre en la configuración de macromanzanas monofuncionales cerradas, resultado de la construcción de proyectos inmobiliarios bajo régimen de copropiedad $o$ de tipo condominio.

Esta situación se asume debido a las superficies prediales mínimas establecidas en el PSCH indicando que para las zonas residenciales donde las superficies van entre $\operatorname{los} 240 \mathrm{~m} 2$ y $800 \mathrm{~m} 2$ (fig.6-A). Por otro lado, las zonas mixtas (ZM1) que incluye equipamiento y habitacional se detallan que deben tener una superficie predial mínima de $540 \mathrm{~m} 2$ sin embargo esta propone un ordenamiento más complejo, con proyección de vivienda desde el 2 do piso y en el 1 er piso otro tipo de programas, como comercial y o de uso público. A pesar de esto en las zonas residenciales un $93 \%$ de las viviendas construidas están proyectadas bajo régimen de la Ley de Copropiedad, configurando predios privados de hasta 10 ha y generando manzanas con deslindes de hasta de $400 \mathrm{~m}$. Por otra parte, las zonas definidas como mixtas (ZM1) se han proyectado solo equipamiento de uso privado como colegios los cuales también generan macromanzanas cerradas y no diversa como lo propuesto en el PSCH. Esto resuelve en la totalidad un sector con manzanas segregadas programáticamente (Fig.6-B). Si analizamos desde esta perspectiva proyecto seccional los porcentajes de usos programáticos según zonas definidos en Seccional y la condición actual de lo ya ejecutado se devela un abandono de la idea de ciudad compacta y de diversidad, claves del nuevo urbanismo; la importancia de la relación de las personas con el espacio público, considerar y apreciar las redes creadas por los diversos usos, entender la manzana como la unidad básica de la ciudad y la primacía de la calle como el aglutinador de la vida de los barrios.

\section{Conclusiones}

Por medio de la revisión del PRCA (1965) y las preexistencias de conjuntos habitacionales modernos se manifiestan en estos ejemplos los beneficios, virtudes y aspectos positivos que se rescatan desde la idea de la zonificación definida como "Centro Vecinal" y el de agrupamiento definida como "Bloque Armónico", descripciones que se relacionan con las ideas del nuevo urbanismo que buscan resolver una planificación urbanaarquitectónica sustentable, prevaleciendo la calidad de vida del habitante por medio de la peatonalización de las ciudades y conectividad urbana, diversidad en uso del suelo y diversidad 
en materia de vivienda, calidad en arquitectura y diseño urbano, estructura tradicional de barrios e incremento en la densidad urbana.

Tanto el urbanismo moderno como el nuevo urbanismo, además de los conceptos estructurantes de ciudad que defienden, proponen que la construcción y desarrollo de ciudades sea desde el reconocimiento del ser humano. En ese sentido, los conjuntos habitacionales Gran Vía y Salar del Carmen marcan el posible camino por el cual puede ser pensada y construida, la ciudad de Antofagasta. Por otra parte, analizando la planificación e intervenciones de las zonas de expansión urbana en la actualidad se reconoce otra intención.

Las superficies prediales mínimas determinadas en el PSCH exaltan la ejecución de proyectos inmobiliarios de tipo condominio privado bajo régimen de copropiedad resultando así una zona monofuncional y sin diversidad programática que no potencia el espacio público.

Para el nuevo urbanismo, una planificación urbana-arquitectónica sustentable se consolida desde el entendimiento de las diversas escalas que componen la ciudad. Debemos entender que las decisiones tomadas a escala de ciudad, deben considerar un diálogo armónico con las dinámicas propias de un vecindario ya que es donde se constituye el espacio público, espacio articulador entre la escala del habitante y la escala de la ciudad. Entonces, ¿Cómo podemos definir una trama que permita la conformación del espacio público de manera de sustentar la articulación habitante y ciudad?

Podemos decir desde los ejemplos expuestos que para la sustentabilidad del espacio público articulador (calle) y así de la ciudad, es necesario la atención en la configuración de la manzana, desde su agrupamiento como también la definición del programa otorgado a las edificaciones que la constituyen, de esta manera la calle no solo cumple solo como un eje estructurante, sino que también cumple con el rol como espacio público articulador de las diversas escalas y actividades del habitante.

\section{Notas}

1 PRC, instrumento de planificación, conjunto de normas de uso de suelo, zonificación, localización de equipamiento, límites urbanos, zona de extensión.

2 PS, instrumento complementario del PRC que establece detalle sobre la zonificación, áreas de construcción obligatoria, de remodelación, conjuntos armónicos, terrenos afectados por expropiación.

3 y de copropiedad (1997), que establece dominio sobre aquellas construcciones, divididas en unidades, emplazadas en un terreno de dominio común; como edificios de departamentos, casas u oficinas. Condominio tipo A y B.

\section{Referencias}

Jacobs, Jane. 1961. Muerte y vida de las grandes ciudades. España: Capitán Swing.

Lynch, Kevin. 1960. La imagen de la ciudad. España: Gustavo Gili.

Clarence, Perry. 2015. "The Neighborhood Unit" from the Regional of New York and its Environs (1929)", de The City Reader, Edited Richard T Le Gates and Fredrick Stout, 486-498. Fifth edition, London and New York, Routledge.

Pavez, Reyes María I. 2008. "Los conceptos de unidad vecinal y de barrio en la teoría y práctica urbanística, antigüedad, siglo XIX y siglo XX”. Serie Doc. UR N${ }^{\circ} 74$, Universidad de Chile.

Terán, Fernando de. 1996. "Calles y algo más que calles". Urbanismo Madrid (n. 29); pp. 6-21. ISSN 0213-9391.

Hernández Amador, Nuria F. 2007. "Aprender a leer la ciudad a través de sus habitantes". Cuadernos de Arquitectura y Nuevo Urbanismo. (2); pp. 51-55.

Hernández, Silverio. 2008. "Introducción al urbanismo sustentable o nuevo urbanismo". Espacios Públicos. (23); pp. 298-307.

Secretaria Comunal de Planificación. 2011. "Memoria explicativa Plan Regulador Comunal, sector norte de Antofagasta".

Secretaria Comunal de Planificación. 1999. "Memoria explicativa Plan Seccional La Chimba". 